University of Nebraska - Lincoln

DigitalCommons@University of Nebraska - Lincoln

$11-3-2003$

\title{
Magnetoresistance in boron carbide junctions
}

\author{
L. Bernard \\ University of Nebraska-Lincoln \\ J. Monson \\ University of Nebraska-Lincoln \\ Andrei Sokolov \\ University of Nebraska-Lincoln, sokolov@unl.edu \\ Zong-Yuan Liu \\ University of Nebraska-Lincoln \\ C.S. Yang \\ University of Nebraska-Lincoln \\ See next page for additional authors
}

Follow this and additional works at: https://digitalcommons.unl.edu/physicsdowben

Part of the Physics Commons

Bernard, L.; Monson, J.; Sokolov, Andrei; Liu, Zong-Yuan; Yang, C.S.; Dowben, Peter A.; Doudin, Bermard; Harken, A.; Welsch, P.; and Robertson, B. W., "Magnetoresistance in boron carbide junctions" (2003). Peter Dowben Publications. 10.

https://digitalcommons.unl.edu/physicsdowben/10

This Article is brought to you for free and open access by the Research Papers in Physics and Astronomy at DigitalCommons@University of Nebraska - Lincoln. It has been accepted for inclusion in Peter Dowben Publications by an authorized administrator of DigitalCommons@University of Nebraska - Lincoln. 


\section{Authors}

L. Bernard, J. Monson, Andrei Sokolov, Zong-Yuan Liu, C.S. Yang, Peter A. Dowben, Bermard Doudin, A. Harken, P. Welsch, and B. W. Robertson 


\title{
Magnetoresistance in boron carbide junctions
}

\author{
L. Bernard, J. Monson, A. Sokolov, Zong-Yuan Liu, C.-S. Yang, P. A. Dowben, \\ and B. Doudina) \\ Department of Physics and Astronomy, and the Center for Materials Research and Analysis (CMRA), \\ Behlen Laboratory of Physics, University of Nebraska-Lincoln, Lincoln, Nebraska 68588-0111
}

\author{
A. Harken, P. Welsch, and B. W. Robertson \\ Department of Mechanical Engineering, N104 Walter Scott Engineering Center, \\ University of Nebraska-Lincoln, Lincoln, Nebraska 68588-0656
}

(Received 3 June 2003; accepted 26 August 2003)

\begin{abstract}
Photoemission and electric transport properties of ferromagnet-insulator-ferromagnet junctions with boron carbide $\left(\mathrm{C}_{2} \mathrm{~B}_{10}\right)$ dielectric barrier are presented. Using a non-oxide barrier confidence avoids oxidation of the interfaces with the ferromagnetic layers. Photoemission confirms chemical abruptness of the interface. Magnetoresistance ratios reaching 50\% are observed at low temperatures, and large nonlinearity in the current-voltage curves show that impurities in the junctions play a key role. (c) 2003 American Institute of Physics. [DOI: 10.1063/1.1621072]
\end{abstract}

Electric transport in ferromagnetic-insulatingferromagnetic systems has attracted a lot of attention since 1995. ${ }^{1,2}$ If the insulating layer is thin enough (less than 2 $\mathrm{nm})$, a significant portion of the electron tunneling probability is modified by the change of relative magnetic alignment of the two ferromagnetic (FM) layers. The related junction magnetoresistance (JMR) of typically $20 \%$ has been observed for a number of magnetic materials, and is being investigated for permanent memory applications. The vast majority of the junctions use $\mathrm{Al}_{2} \mathrm{O}_{3}$ oxide as an insulating barrier. It is a well-established material, but investigations of other barriers are necessary if we are to completely understand the physics of tunneling from magnetic materials. For example, de Teresa et al. ${ }^{3}$ showed that modifying the insulator changes the spin polarization value, and may even change its sign. If we recall that the electronic properties of the interface are key for controlling the spin polarization, it is not surprising that changing the barrier modifies the JMR properties. There is also a need for studying barriers without oxides. Oxide modification of the ferromagnet interface is experimentally very challenging to characterize, and electron microscopy analytical techniques lack single atomic plane resolution. Our results on chromium oxide/cobalt interface, ${ }^{4}$ and other studies of nickel oxide/cobalt interfaces ${ }^{5,6}$ have demonstrated that a transition metal (cobalt) will oxidize at the buried interface.

We present a different type of barrier, without oxides, for applications in magnetic tunnel junctions. The low $Z$ inorganic boron carbide $\left(\mathrm{C}_{2} \mathrm{~B}_{10}\right)$ can be grown by chemical vapor deposition without pinholes in the ultrathin film regime. Plasma enhanced chemical vapor deposited (PECVD) boron carbide is an excellent dielectric with resistivities in the range of $10^{10}$ to $10^{13} \Omega \mathrm{cm}$, with a band gap that can be adjusted from $0.7 \mathrm{eV}$ to $1.9 \mathrm{eV}$ by altering the boron to carbon ratio $^{7}$ and to band gap values well above $2.7 \mathrm{eV}$ by adding phosphorus to the alloy. ${ }^{8}$ Tunnel diode junctions devices made with boron carbide have been already shown in

a)Electronic mail: bdoudin@unl.edu our laboratories. ${ }^{9}$ The experimental band mapping effort of Osterwalder's group ${ }^{10,11}$ has provided evidence of changes in the spin-dependent Fermi surface(s) when $h$-BN overlayers are deposited on $\mathrm{Ni}(111)$, but the magnetic surface states appear to be enhanced and not suppressed by the overlayer. This suggests that boron-based barrier layers may be less likely than many other materials to suppress the interface magnetization: key to a good tunnel junction. ${ }^{12,13}$ Indeed, a magnetoresistive device has been fabricated using boron nitride as the dielectric (insulating) barrier layer. ${ }^{14}$

Magnetic junctions were fabricated on insulating lanthanum oxide or $\mathrm{Si} / \mathrm{SiO}$ wafer substrates on which several horizontal lines of cobalt were sputter deposited. Argon etching was performed to clean the Co surface prior to the deposition of the $\left(\mathrm{C}_{2} \mathrm{~B}_{10}\right)$ film. The $13.56 \mathrm{MHz}$ rf PECVD system used orthocarborane as the precursor, schematically shown in Fig. 1 (III). Orthocarborane (closo-1,2- $\mathrm{C}_{2} \mathrm{~B}_{10} \mathrm{H}_{12}$ ) has been shown to be an effective source molecule ${ }^{8,9,15}$ for the deposition of a $\mathrm{C}_{2} \mathrm{~B}_{10}$ film of resistivity values well in excess of $10^{13} \Omega \mathrm{m} .{ }^{15}$ The indirect band gap of about $0.75 \mathrm{eV}$ and a direct band gap of about $1.5 \mathrm{eV}$ can be estimated from the absorption coefficient. ${ }^{15}$ Nonetheless, based upon the photoemission, the $\mathrm{C}_{2} \mathrm{~B}_{10}$ density of states remains appreciably low within $2-3 \mathrm{eV}$ of the Fermi level following extensive electron and photon radiation and is observed to remain quite low within $1 \mathrm{eV}$ of the Fermi level for $\mathrm{C}_{2} \mathrm{~B}_{10}$ fabricated by PECVD, ${ }^{16}$ as confirmed by our own measurements. The $\mathrm{C}_{2} \mathrm{~B}_{10}$ film thickness was varied between 1 and $10 \mathrm{~nm}$. A cross geometry was used for evaporating the top cobalt layer under the same conditions as the bottom layer, resulting in a Co thickness of $30 \mathrm{~nm}$, estimated using a quartz crystal thickness monitor. Typical size of our junctions is $10 \mu \mathrm{m}$ $\times 200 \mu \mathrm{m}$. Areas down to $10 \mu \mathrm{m} \times 10 \mu \mathrm{m}$ were also made for electric measurements, using optical lithography to pattern a bottom Co line.

Combined photoemission, inverse photoemission, and angle resolved x-ray photoemission (XPS) studies were undertaken to characterize the quality of the interface. ${ }^{4}$ The He I $(21.2 \mathrm{eV})$ ultraviolet photoemission, angle-resolved in- 

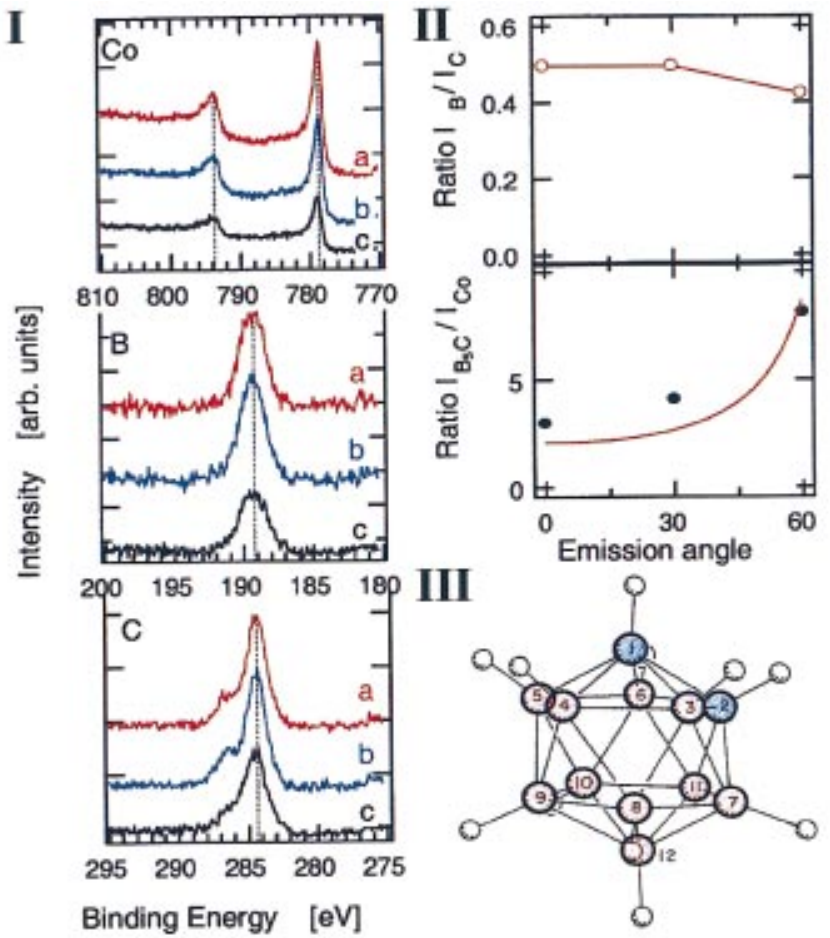

FIG. 1. (Color) (I) X-ray photoemission spectra for a cobalt film after orthocarborane adsorption, measured at $150 \mathrm{~K}$, for the cobalt $2 p$, boron $1 s$, and carbon $1 s$ core levels are shown on the left-hand side. Normal emission in indicated in red (a), $30^{\circ}$ off normal emission in blue (b), and $60^{\circ}$ off normal emission in black (c). (II) The x-ray photoemission intensity ratios of boron to carbon boron plus carbon to cobalt intensity ratios, following decomposition, have been plotted as a function of emission angle, from spectra similar to those obtained in (I). A model based on an overlayer thickness of $12 \AA$ thick was used to fit the intensity ratio plot. (III) Schematic of the orthocarborane $\left(1,2-\mathrm{C}_{2} \mathrm{~B}_{10} \mathrm{H}_{12}\right)$. No evidence of cobalt carbide or cobalt boride formation was found before or after deposition of the adsorbed carborane.

verse photoemission, and XPS $(1253.6 \mathrm{eV})$ were undertaken in a single UHV chamber ${ }^{4}$ and binding energies were referenced to the Fermi level. A fresh cobalt substrate surface was prepared prior to each run by thermal evaporation. The orthocarborane was adsorbed on the surface from the vapor and then decomposed by electron irradiation.

The adsorption of orthocarborane at $150 \mathrm{~K}$ results in the diminution of the cobalt $d$ bands and the growth of the characteristic levels representative of the molecular orbitals of orthocarborane. ${ }^{17-19}$ Because the highest occupied to lowest unoccupied molecular orbital gap of adsorbed orthocarborane is so large ( 9 to $10 \mathrm{eV}$ in experiment and $11 \mathrm{eV}$ in theory), ${ }^{18,19}$ the cobalt $3 d$ bands can still be observed through a thin film of adsorbed orthocarborane $12 \AA$ thick. The residual signals from the underlying cobalt $3 d$ bands, in both photoemission and inverse photoemission, are not significantly perturbed by orthocarborane adsorption. This is consistent with XPS measurements: on clean cobalt films where $2 p_{3 / 2}$ and $2 p_{1 / 2}$ binding energies are $778.4 \pm 0.1 \mathrm{eV}$ and 793.4 $\pm 0.2 \mathrm{eV}$. The shift of these core-level binding energies to the higher binding energies of $778.9 \pm 0.1 \mathrm{eV}$ and $794 \pm 0.2 \mathrm{eV}$, nonetheless, is closer to the shift expected for the surface to bulk core-level shift of cobalt or cobalt bonded in a ligand field, rather than formation of a carbide. ${ }^{20}$ The absence of significant core-level shifts of cobalt and boron and the combined photoemission and inverse photoemission Downloaded 05 Sep 2006 to 129.93.16.206. Redistribution subject

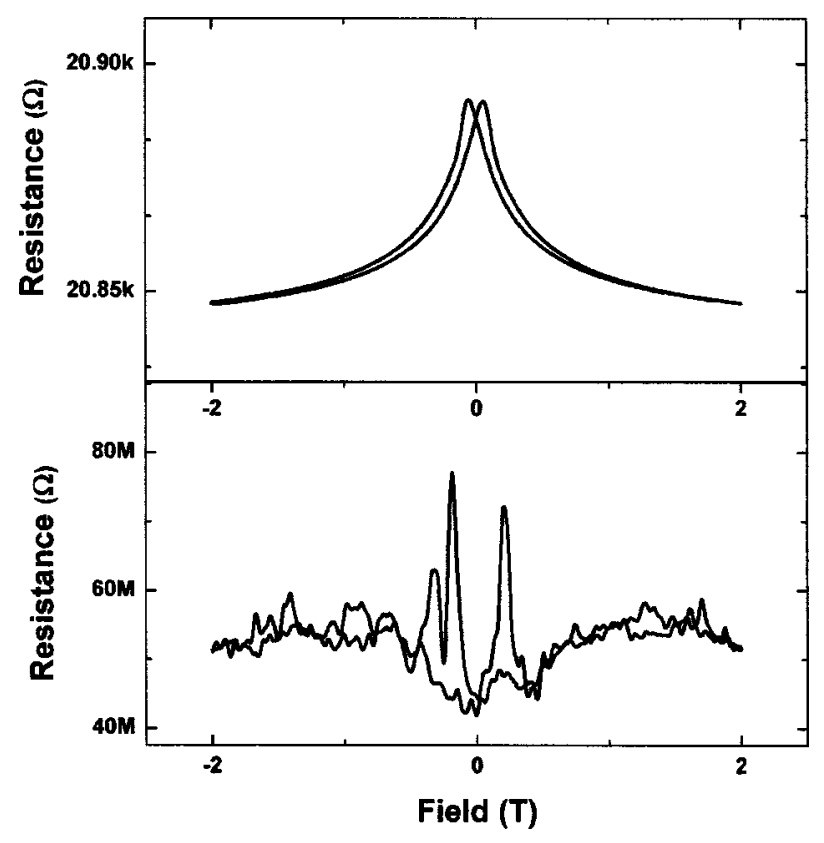

FIG. 2. Resistance of $\mathrm{Co} / \mathrm{B}_{5} \mathrm{C} / \mathrm{Co}$ junctions as a function of magnetic field, measured at $1.6 \mathrm{~K}$. Top: Small resistance sample, with less than $1 \%$ JMR. Bottom: Large resistance sample, with large and noisy JMR.

confirm that the interface between cobalt and the adsorbed orthocarborane is abrupt. Furthermore, we are able to conclude that strong chemical reactions that result in carbide formation or cobalt dissolution in the molecular overlayer do NOT occur.

With changing emission angle, the main core-level XPS lines do not shift in binding energy, as seen in Fig. 1 (I), for the cobalt $2 p$ and boron $1 s$ core levels. The exception is the carbon $1 s$ XPS spectra which have a satellite line $\left(\mathrm{C}_{s}\right)$ at $286.5 \pm 0.3 \mathrm{eV}$ binding energy that is greater in intensity for normal emission (a) and diminishes in intensity with $30^{\circ}$ off normal emission (b) and diminishes further still at $60^{\circ}$ off normal emission (c) relative to the main carbon $1 s$ peak $\left(\mathrm{C}_{p}\right)$. This is summarized in Fig. 1(I). This change in the contributions to the carbon $1 s$ could be a result of preferential orientation of carborane cage at the cobalt interface or screened and unscreened final states. ${ }^{17}$ Such effects, at the cobalt interface, will be strongest at normal emission where the effective probing depth is deeper than at $60^{\circ}$ off normal emission. The boron to carbon ratio remains relatively constant with emission angle, as plotted in Fig. 1 (II), indicating that the molecular film is a result of associative adsorption and the $\mathrm{C}_{2} \mathrm{~B}_{10}$ ratio is preserved. Similar results are obtained after photon and electron induced decomposition and analyzed as in Fig. 1(II). Photon, electron irradiation, and plasma assisted decomposition of the closo-1,2,dicarbodecaborane result in a boron-carbon alloy with similar semiconducting properties ${ }^{21}$ in which the photoemission signature of the icosahedral cage is preserved in all cases. The exopolyhedral hydrogen loss (whose evolution can be detected in a quadrupole mass spectrometer) seems to be the dominant process in all three deposition methods. We expect therefore that the photoemission information is directly applicable to the PECVD samples made for magnetoelectronic purposes.

Characterization of the electric transport properties in 


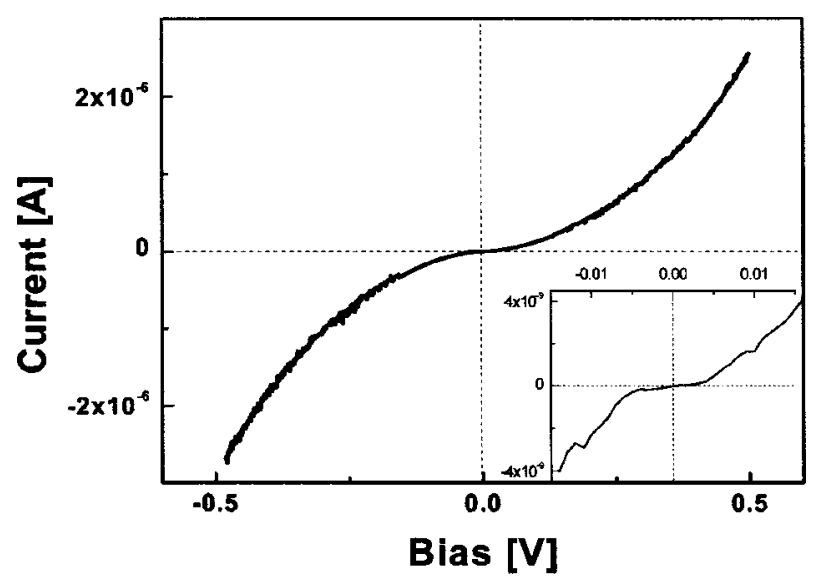

FIG. 3. $I-V$ of a $\mathrm{Co} / \mathrm{B}_{5} \mathrm{C} / \mathrm{Co}$ junctions of large resistance. Inset is an enlargement of the low-voltage curve, showing a blockade of current for voltage bias smaller than $5 \mathrm{mV}$.

these samples were performed using standard dc and ac techniques, exchanging current and voltage leads to check the absence of Hall or extraordinary Hall contributions to the observed magnetoresistance. Two categories of samples were found. Devices with a resistance area product of values typically in the range of $10^{7} \Omega(\mu \mathrm{m})^{2}$, related to rather thin barriers (around $2 \mathrm{~nm}$ ), showed small magnetoresistance effects, without significant bias and temperature dependence (Fig. 2, top). The current-voltage $(I-V)$ curves showed no deviations of more than $2 \%$ from ohmic behavior. The junction resistance value more than one order of magnitude larger than those of the leads exclude a significant contribution of anisotropic magnetoresistance to our observations. The observed JMR did not change by more than $10 \%$ when varying the temperature between 1.6 and $300 \mathrm{~K}$, and the voltage bias between -1 and $+1 \mathrm{~V}$. A slight decrease of $20 \%$ of the resistance when lowering the temperature suggests the existence of a pinhole short in the junctions, or a heavily doped semiconducting barrier junctions. The second type of samples showed significantly larger JMR of more than 50\% at low temperatures, with resistance area product between $10^{10}$ and $10^{11} \Omega(\mu \mathrm{m})^{2}$, related to thicker barriers (Fig. 2 bottom). These samples exhibited "noisy" features and strong variation of JMR with temperature and voltage bias. The JMR decreased down to a few percent when increasing the temperature to a few tens of Kelvin, in contrast to the first type of samples. The resistance decreased exponentially by two to three orders of magnitude when heating the sample up to room temperature. The fact that $\mathrm{C}_{2} \mathrm{~B}_{10}$ has a band gap limited to approximately $1 \mathrm{eV}$ and the possible existence of intermediate levels make plausible an electrical current transport through intermediate states in the barrier. Hopping conduction and/or resonant tunneling ${ }^{22}$ allows spin-conserving transport processes to exist, and significant tunneling magnetoresistance remains present in the junctions. For highresistivity samples, very pronounced zero-bias anomaly is revealed in the $I-V$ curves at low temperatures (Fig. 3), which is characteristic of an electrostatic Coulomb blockade effect. We observed that the JMR decreases exponentially with voltage bias, down a few percent at bias larger than the blockade bias value ( $5 \mathrm{mV}$ for the examples of Fig. 3).

$\mathrm{C}_{2} \mathrm{~B}_{10}$ junctions have been shown to make abrupt interfaces with a FM material, and significant magnetoresistance values were observed at low temperatures. We have the first experimental evidence that $\mathrm{C}_{2} \mathrm{~B}_{10}$ barriers are a possible alternative for making insulating junctions between magnetic materials. Our first results indicate that improvements in maximizing the band gap of these boron carbide barriers and minimizing their defects density are necessary for competing with $\mathrm{Al}_{2} \mathrm{O}_{3}$ tunnel junctions. The former improvement is certainly possible. ${ }^{8}$

This research was supported by the Office of Naval Research and the National Science Foundation (Grant No. ECS0300018). The authors would like to thank Camelia Borca and A. Caruso for their technical assistance.

${ }^{1}$ J. S. Moodera, J. Nassar, and G. Mathon, Annu. Rev. Mater. Sci. 29, 381 (1999).

${ }^{2}$ E. Y. Tsymbal, O. N. Mryasov, and P. R. LeClair, J. Phys.: Condens. Matter 15, R109 (2003).

${ }^{3}$ J. M. de Teresa, A. Barthelemy, A. Fert, J. P. Contour, F. Montaigne, and P. Seneor, Science 286, 507 (1999).

${ }^{4}$ R. Cheng, C. N. Borca, N. Pilet, B. Xu, B. Doudin, S. H. Liou, and P. A. Dowben, Appl. Phys. Lett. 81, 2109 (2002).

${ }^{5}$ H. Ohldag, T. J. Regan, J. Stöhr, A. Scholl, F. Nolting, J. Luning, C. Stamm, S. Anders, and R. L. White, Phys. Rev. Lett. 87, 247201 (2001).

${ }^{6}$ T. J. Regan, H. Ohldag, C. Stamm, F. Nolting, J. Luning, J. Stöhr, and R. L. White, Phys. Rev. B 64, 214442 (2001).

${ }^{7}$ S. Lee, J. Mazurowski, G. Ramseyer, and P. A. Dowben, J. Appl. Phys. 72, 4925 (1992).

${ }^{8}$ D. N. McIlroy, S.-D. Hwang, K. Yang, N. Remmes, P. A. Dowben, A. A. Ahmad, N. J. Ianno, J. Z. Li, J. Y. Lin, and H. X. Jiang, Appl. Phys. A: Mater. Sci. Process. 67, 335 (1998).

${ }^{9}$ S.-D. Hwang, K. Yang, P. A. Dowben, A. A. Ahmad, N. J. Ianno, J. Z. Li, J. Y. Lin, H. X. Jiang, and D. N. McIlroy, Appl. Phys. Lett. 70, 1028 (1997).

${ }^{10}$ T. Greber, W. Auwärter, and J. Ostwalder, in The Physics of Low Dimensional Systems, edited by J. L. Moran-Lopez (Plenum, New York, 2000).

${ }^{11}$ J. Osterwalder, J. Electron Spectrosc. Relat. Phenom. 117, 71 (2001).

${ }^{12}$ I. I. Mazin, Phys. Rev. Lett. 83, 1427 (1999).

${ }^{13}$ J. Mathon, Phys. Rev. B 56, 11810 (1997).

${ }^{14}$ R. A. Lukaszew, Y. Sheng, C. Uher, and R. Clarke, Appl. Phys. Lett. 75, 1941 (1999).

${ }^{15}$ Ahmad A. Ahmad, N. J. Ianno, P. G. Snyder, D. Welipitiya, D. Byun, and P. A. Dowben, J. Appl. Phys. 79, 8643 (1996).

${ }^{16}$ I. Jimenez, L. J. Terminello, F. J. Himpsel, M. Grus, and T. A. Callcott, J. Electron Spectrosc. Relat. Phenom. 103, 611 (1999).

${ }^{17}$ L. Bernard, A. N. Caruso, B. Xu, B. Doudin, and P. A. Dowben, Thin Solid Films 428, 253 (2003).

${ }^{18}$ D. N. Mcllroy, C. Waldfried, T. McAvoy, J. Choi, P. A. Dowben, and D. Heskett, Chem. Phys. Lett. 264, 168 (1997).

${ }^{19}$ A. N. Caruso, L. Bernard, B. Xu, and P. A. Dowben, J. Phys. Chem. (to be published).

${ }^{20}$ Handbook of X-ray Photoelectron Spectroscopy (Perkin Elmer Corp., Physical Electronics Division, 1992), pp. 82-83.

${ }^{21}$ D. Byun, B. R. Spady, N. J. Ianno, and P. A. Dowben, Nanostruct. Mater. 5, 465 (1995).

${ }^{22}$ E. Y. Tsymbal, A. Sokolov, I. F. Sabirianov, and B. Doudin, Phys. Rev. Lett. 90, 186602 (2003). 